\title{
Health Informatics Master Program at King Saud bin Abdulaziz University for Health Sciences, Riyadh, Saudi Arabia
}

\author{
M. Altwaiijiri, B. Aldosari \\ College of Public Health and Health Informatics, King Saud bin Abdulaziz University for Health \\ Sciences (KSAU-HS), Riyadh, Saudi Arabia
}

\begin{abstract}
Summary
Objective: The purpose of this paper is to describe the Health Informatics Master Program at King Saud bin Abdulaziz University for Health Sciences (KSAU-HS), Riyadh, Saudi Arabia.

Methods: We have reviewed health informatics master programs worldwide with more emphasis on the recommendations of the International Medical Informatics Association on education in health informatics, research, and faculty/trainee participation at KSAU-HS.

Results: An applied health informatics master program has been designed where graduates will be able to deploy information and communication technology in support of health systems' processes. This is due to the fact that most of heal th organizations are driven by information and communication technology. The program embodies the features of effective applied health informatics master programs recommended by the International Medical Informatics Association on education in health informatics and delineated as curricula integrating three areas of knowledge and skills: 1) Methodology and technology for the processing of data, information and knowledge in medicine and healthcare, 2) Medicine, health and biosciences, and 3) Informatics/ computer science, mathematics and biometry. Conclusions: The health informatics master program (MHI) immerses students in the multidisciplinary field of health informatics education. Graduates of the MHI program will be well- prepared informaticians for leadership positions, able to meet the increasing demands in the field of health informatics to manage, plan, develop, and provide expert consultations to the healthcare sectors.
\end{abstract}

\section{Keywords}

Health Informatics, Health information management Education, Health Information Systems, and Health Studies

Geissbuhler A, KulikowskiC, editors. IMIA Yearbook of Medical Informatics 2008. Methods Inf Med 2008; 47 Supp 1: 145-9

\section{Background}

Work on this program began in 2004 with an assessment of the possibility of developing a graduate level program in health informatics, given the pressing need to develop a solid body of knowledge and practice for the appropriate management, gathering and use of information in healthcare in the hands of qualified health informatics leaders.

Over the time, we have done a number of tasks to move this proposal forward. Nationally, we have examined local institutions in order to get a clear vision and guidelines for the mechanism for proposing graduate programs based on the Saudi Higher Education Standards. We also, have consulted with the Ministry of Higher Education to provide us with standard criteria that meet the Ministry of Higher Education approval for graduate programs.

Internationally, we have examined relevant literature, and consulted with the University of Sydney, Australia and the University of Pittsburgh, USA to determine the best contents and process for the proposed program in Health Informatics.

Moreover, we have benefited greatly from the recommendations of the International Medical Informatics Association (IMIA) on Education in Health and Medical Informatics. These recommendations were developed to support the education of medical informatics internationally.

\section{Introduction}

The healthcare industry, not only in Saudi Arabia but also worldwide, has become increasingly reliant upon information and communication technologies (ICT). This has resulted in a significant technology gap between those professionals entrusted with providing clinical care and those who are in charge of managing the complex information systems required to operate modern healthcare systems. Such gap threatens the effective and efficient management of healthcare information. The need to use ICT in healthcare has resulted in a new science called Health Informatics (HI) which is a socio-technical discipline concerned with the use of ICT to support the delivery of healthcare. [1] It is a broad discipline that includes many subjects such as bio-informatics, electronic patient records, telemedicine, clinical decision-making, etc. [2]

IMIA has made significant efforts to promote and enhance health informatics education worldwide. IMIA suggested that proper education is essential for healthcare professionals to meet the increasing demand for health informatics. [3] Such education would enable health professionals to take full advantage of ICT. A special issue of the International Journal of Medical Informatics (Volume $73,2004)$ was dedicated to health informatics education. The special issue is comprised of papers presented at 2003 IMIA working group on Education Meet- 
ing which was attended by 80 educators from all over the world.

In the light of the above, King Saud bin Abdulaziz University for Health Sciences (KSAU-HS) is offering a Master of Science degree in Health Informatics (MHI) to provide advanced $\mathrm{HI}$ education and to prepare HI specialists who can facilitate the transfer and interpretation of patient information in order to enhance the quality of healthcare delivery.

The design of the two-year program follows the recommendations of IMIA on education in health and medical informatics[3]. The program targets health professionals (such as physicians, nurses, pharmacists, therapists and laboratory, radiology technologists, etc...) as well as IT professionals working in the health sector.

The program is designed to equip graduates with state of the art technical, humanistic and practical skills in health informatics to meet the growing demands in the field of health informatics. Graduates of this program will fill very specific roles as informaticians who are able to work in public and private healthcare systems to lead the management, planning and implementation of health information systems.

Although degree programs are available at the Master of Science level in areas of health administration or other health related fields, there is no graduate health informatics program available nationally at the graduate levels. Additionally, the highly recognized Saudi Arabian National Guard Medical Centers along with KSAU-HS provide this program with qualified faculty and a variety of wealthy graduate level courses that produce essential ingredient to attract national competitive students. This will eliminate barriers associated with Saudi students pursuing graduate studies in the field of Health Informatics abroad.

The purpose of this paper is to introduce the master program of health informatics at KSAU-HS, Saudi Arabia. The program is considered to be an applied health informatics program of which the graduates should be able to deploy ITC in support of health systems processes. This is due to the fact that most of health organizations in Saudi Arabia are deploying technology "as-is". The paper explains the process used to develop the program including needs identification, academic development, and institutional development. The paper also addresses the implementation and evaluation processes.

\section{Recommendations for Health and Medical Informatics Education}

IMIA has proposed a set of recommendations on education which provides an excellent foundation for health informatics education.[3] These recommendations have evolved from seven conferences organized by the Working Group for Health and Medical Informatics Education. Such recommendations are not only important to provide an education framework but also provide a basis for establishing an international collaboration that enables international exchange of standards and teachers. The IMIA recommendations are grouped into two sets:

1. The first set is concerned with the recommendations of courses in health and medical informatics as part of educational programs such as medicine, nursing, pharmacy, computer science and other programs. The objective of this set is to enable healthcare professionals to become good IT users.

2. The second set is concerned with the recommendations of courses for dedicated educational programs in health informatics in order to prepare graduates to become health informatics specialists.
In this paper, the main focus is put on the second set of recommendations, presenting a dedicated Master Program in Health Informatics aimed to prepare graduates for career in the health informatics field.

The recommendations identify the level of knowledge and skills required for each learning outcome. The knowledge and skills are grouped into three domains:

1. Health Informatics

2. Medicine, health, and health services management

3. Informatics, mathematics, and biometry

IMIA also indicates the level of knowledge and skills required as advanced, intermediate, or basic.

\section{IMIA Recommendations for Master Programs in Health and Medical Informatics}

The main goal of dedicated HI programs, as suggested by IMIA, is to provide a scientific education that includes theory, specialized knowledge, and practical skills. Graduates shall be able to:

- Apply a practice-oriented methods and tools from health and medical informatics.

- Participate in research and in the methodical advancement within the field of health and medical informatics.

IMIA recommends that master programs accept students with one of following educational degrees:

- A bachelor degree in health information management

- A bachelor degree in medicine or health sciences

- A bachelor degree in computer science Based on the recommendations of IMIA on Education in Health Informatics, the program is considered as an applied health informatics approach that supports health informatics graduate program at the KSAU-HS. It shares a 
strong focus on interdisciplinary coursework and research.

The following description of health informatics master program development process at KSAU-HS illustrates the foundation for productive health informatics graduate program.

1. Reviewed most of existing health informatics education programs in terms of their objectives, candidates, contents, and outcomes.

2. Reviewed the IMIA recommendations on education in health and medical informatics.

3. Reviewed the literature on HI education.

4. Organized workshops with select participants based on a stakeholder analysis including: HI scientific project team, HI teachers, potential HI students, and employers.

5. Identified an initial list of courses mapped to the list of knowledge and skills suggested by IMIA.

\section{Competences of the Health Informatics Master Program}

The mission of the Program is to advance the quality and efficiency of the Saudi healthcare system through improved information management, communication and the generation of new forms of knowledge. The program strives to produce qualified informaticians who can effectively partner with and/or lead healthcare professionals in developing, applying, and evaluating the use of information technology to respond to the changing dynamics in healthcare.

The MHI program actively supports the central mission of the department of Health Informatics by facilitating innovative educational and research programs, providing leaderships within program disciplines to meet current industry challenges, and ensuring that graduates have a competitive edge in the increasingly demanding health informatics nationally and internationally. This will be achieved in cooperation with other universities and research centers applying international educational standards endorsed by the IMIA. Health informatics is a rich and diverse field with important contributions from many disciplines. A major objective of the Master of Science degree program in health and medical informatics is to provide students with an understanding of the multifaceted, interdisciplinary nature of computing in healthcare.

The primary objectives of the MHI are to:

1. Provide students with in- depth, specialized knowledge in $\mathrm{HI}$ and other skills required by informaticians to track and follow the trends in the field of health informatics and other areas impacted by health informatics in health systems.

2. Provide students with the skills and practical experience needed to enhance the implementation of health informatics applications.

3. Provide students with the required skills to enable them to diagnose and provide solutions to barriers associated with health informatics planning, development, implementation and usage.

4. Provide informaticians with leadership and collaborative skills needed to enhance the management of health informatics.

5. Prepare health informaticians to work closely with key stakeholders as a facilitator of collaborations between information technology departments and health system professionals.

6. Provide graduates with the foundation to conduct $\mathrm{PhD}$-level research in HI.

\section{Program Infrastructure}

The program depends on the following infrastructure:

- A Program level Academic Council and director with strong cred- ibility in academic and health informatics.

- Faculty members with a clear vision and philosophy, who value their students and the teaching.

- Effective collaborations with local and international academic institutions. Some of these will be able to provide part time teaching, research and project mentoring opportunities.

\section{MHI Program Structure and Curriculum}

The Masters program in Health Informatics is a dedicated full- time, two-year program. It is organized in modules (courses) consisting of 3 hours of lectures per week excluding the time spent for exercises, seminars, and practicum. It requires a minimum of 14 courses totaling 42 semester credit hours (a credit hour is equivalent to an hour of lecture a week for a semester of 16 weeks. Three semester credit hour are equivalent to 6 ECTS of course work) [4]. The program of study includes a variety of graduate level foundation courses, required health informatics, informatics and health and medical sciences courses.

Students must complete two-foundation courses dependant on the student background. Students are also required to complete successfully seven courses from the health informatics knowledge area as well as two courses from the knowledge area of medical, health sciences, and health system organization. Finally, students are required to complete three courses from Informatics knowledge area.

The HI courses listed in Table 1 are common in most Health informatics programs reviewed except for the HI 561 course that is concerned with the legal, ethical, and social aspects of HI. The introduction of ICT into healthcare raises some ethical, legal, and social 
issues. Very few health informatics programs address these issues in a formal way.[5] Ethical education should be as important as clinical and technical education for health professionals. Some of the ethical issues include:

- Health information on the web that does not come from reliable sources may be inaccurate.

- The web is also changing the doctor-patient relationship, as some patients seek information on certain health issues from the web without consulting their doctors.

- Electronic Medical Record (EMR) systems present an issue of confidentiality due to probable breaches of security. The ownership of the health information is becoming an issue.

- Telemedicine raises an issue whether physicians can practice medicine (through ICT tools) in a remote country in which they do not have a practicing license.

Due to these ethical issues, the Masters Program in Health Informatics at KSAU-HS offers a dedicated course addressing most of the ethical, legal, social aspects of health informatics.

The selection of informatics courses was influenced by the survey conducted by Logan et al.[6] of HI specialists with Master's level credentials that asked about computer science topics or skills they need in their employment. In this survey, the topics of database design and web technology are given a high rating while the topic of network management is given a low rating. As a result of this study, the Master Program of Health Informatics at KSAU-HS offers an advanced database course consisting of a database design and management. Another course is also offered to meet the need for advanced skills and knowledge in web-related subjects including database interface. Even though the program does not have a dedicated course in network management, general networking concepts are covered in other IT courses.
Furthermore, proper project management is one of the critical success factors for information systems implementation. [7] In addition, due to the fact that a lot of hospitals in Saudi Arabia are going through automation projects including the deployment of health informatics applications, the Master program offers a dedicated course in IT project management. This course provides students with the knowledge, skills, tools, and techniques to organize, execute, and monitor the work of healthcare IT project activities in order to meet the expectation of stakeholders. The content of these courses is presented in Table 1.

\section{Conclusions}

Health informatics graduate program at KSAU-HS is considered to be an applied health informatics approach that supports health informatics graduate program at the KSAU-HS. It shares a strong focus on interdisciplinary coursework and research. The MHI program illustrates how graduate students can be highly productive when they graduate from the program. MHI fosters a creative synergy that advances health informatics across multiple fronts and prepares graduates of MHI program to participate in an evolving and multidisciplinary fields such as health informatics research, academics institutions, healthcare institutions, health insurance companies, and health information technology vendors.

The KSAU-HS MHI is considered to be the first of its kind in the Middle East. In order to analyse similarities and differences with other western graduate health informatics programs, we have compared our MHI program with the University of Sydney Master of Health Informatics Program, (Sydney, Australia) [8], the University of Pitts-
Table 1 MHICurriculum

\begin{tabular}{|c|c|}
\hline \multicolumn{2}{|c|}{ Foundation Courses (2 required) } \\
\hline Course Code & Course Name \\
\hline HI 500 & $\begin{array}{l}\text { Fundamentals of Med. \& Medical } \\
\text { Terminology }\end{array}$ \\
\hline HI 501 & Introduction to Information Technology \\
\hline HI 502 & Statistical Analysis \\
\hline HI 503 & Introduction to Health Informatics \\
\hline \multicolumn{2}{|c|}{ Required Health Informatics Courses (6 required) } \\
\hline Course Code & Course Name \\
\hline HI 503 & Introduction to Health Informatics \\
\hline HI 531 & Health Information Systems \\
\hline HI 532 & Electronic Health Records \& Standards \\
\hline HI 561 & Legal Ethical \& Soc. Asp. of HI \\
\hline HI 562 & $\begin{array}{l}\text { Decision Support \& Knowledge } \\
\text { Management }\end{array}$ \\
\hline HI 570 & Health Informatics Project \\
\hline \multicolumn{2}{|c|}{ Elective Health Informatics Courses (1 required) } \\
\hline Course Code & Course Name \\
\hline HI 533 & $\begin{array}{l}\text { Information Technology and Management } \\
\text { in Healthcare }\end{array}$ \\
\hline HI 564 & Topics in Health Informatics \\
\hline HI 566 & Direct Study in Health Informatics \\
\hline \multicolumn{2}{|c|}{ Required Informatics Courses (3 required) } \\
\hline Course Code & Course Name \\
\hline HI 539 & Web Technology \\
\hline HI 560 & Database Design \& Management \\
\hline HI 565 & IT Project Management \\
\hline \multicolumn{2}{|c|}{ Required Medical and Health Courses } \\
\hline Course Code & Course Name \\
\hline HI 540 & Research Methods \\
\hline \multicolumn{2}{|c|}{ Elective Medical and Health Courses (1 required) } \\
\hline Course Code & Course Name \\
\hline HI 535 & Health Services Administration \\
\hline HI 536 & International Health Systems \\
\hline HI 537 & $\begin{array}{l}\text { Financial Management of Health } \\
\text { Organization }\end{array}$ \\
\hline HI 538 & Organizational Behavior in Healthcare \\
\hline
\end{tabular}


burgh (PA, USA) Master of Health Information Systems Program [9] and the Dalhousie University (Fairfax, Canada) Health Informatics Master Program [10]. The comparison suggests that KSAU-HS MHI is likely similar to the mentioned western graduate program, but having extra courses, such as, Fundamentals of Medicine \& Medical Terminology for IT background students and Introduction to Information Technology for health sciences background students makes KSAU-HS MHI program unique. The reason behind adding those two courses in the first semester is to make all freshmen students who came from different discipline as homogenous as possible.

Finally, proper education in health informatics is essential to help fill the technology gap between healthcare professionals entrusted with providing healthcare and those who are in charge of managing the complex information systems required to operate modern healthcare organizations. In this paper, we have introduced the Master program in health informatics in a newly founded Saudi university specialized in health sciences. The two-year program is based on the recommendations of IMIA on education in health and medical informatics.

The Master program started in 2005 and has already celebrated the first 25 graduates on June 2007. The graduation ceremony was attended by high officials in Saudi Arabia. IMIA was also presented in the ceremony through a video message speech by the IMIA president elect Prof. Reinhold Haux. In order to ensure that the aim of the program has been realized, in addition to the proper selection of the MHI courses, the department of health informatics engages MHI students during their last year in researches and creative projects activities in the field of health informatics or related areas.

Table 2 MHI Graduated Students Job Distribution

\begin{tabular}{|llllllll|}
\hline Gender & $\begin{array}{l}\text { Academic/ } \\
\text { Researcher }\end{array}$ & $\begin{array}{l}\text { Clinical } \\
\text { Data } \\
\text { Manager }\end{array}$ & $\begin{array}{l}\text { Clinical } \\
\text { Information } \\
\text { Manager }\end{array}$ & $\begin{array}{l}\text { Health } \\
\text { Informatics } \\
\text { Consultant }\end{array}$ & $\begin{array}{l}\text { Systems } \\
\text { Analyst }\end{array}$ & $\begin{array}{l}\text { Systems } \\
\text { Analyst }\end{array}$ & Grand Total \\
\hline Male & & 2 & 1 & 2 & 3 & 1 & 9 \\
Female & 5 & 3 & 1 & 3 & 2 & 2 & 16 \\
Total Num & 5 & 5 & 1 & 5 & 5 & 3 & 25 \\
$(25)$ & & & & & & & \\
\hline
\end{tabular}

An example of that researches and projects, Developing an Ideal Models for Clinical Information Systems, Developing a Strategic Plan for the Saudi Association for Health Informatics, Developing an Initiative Plan Toward Saudi National Electronic Health Records, Developing Criteria for Electronic Health Records Planning Steps, etc..

Furthermore, the department of health informatics develops a graduate recruitment program to assess the MHI graduate recruitment with the local public and private healthcare sectors. The graduate recruitment program enables MHI graduate students to operate in a more dynamic role in as health informatics professional in the healthcare sector, as illustrated in table 2. Table 2 shows a distribution of all the 25 graduate students along with their opportunities after they graduate from the MHI program. Five female graduates have pursued health informatics academic and research discipline. Two male and three female have been promoted to clinical data manager positions. One female and one male have become clinical information managers. Tow male and three female are working as health informatics consultants. Three male and two female have been prompted as director of health information systems. The remaining three graduates are working as system analyst. Based on that, the program likely moving forward to achieve its goals and meet its objectives.

\section{Acknowledgment}

The authors would like to acknowledge the support of the KASU-HS senior management including Dr. A. AlRabeeah and Dr. B. Al-Kanawy. Special thanks are also due to the faculty of the program; Dr. A. Al-Barak, Dr. M. Al-Yemni, Dr. H. Altuwaijri, and Dr. B. Al-Omar.

\section{References}

1. Hovenga EJ. Globalization of health and medical informatics education-what are the issues? Int J Med Inform 2004;73:101-9.

2. IMIA. IMIA scientific map. Available at: www.imia.org. Accessed July 4, 2005.

3. International Medical Informatics Association, Working Group 1: Health and Medical Informatics Education. Recommendations of the International Medical Informatics Association (IMIA) on Education in Health and Medical Informatics. Methods Inf Med.2000;39:267-77.

4. European Commission. The description of European Credit Transfer and Accreditation System. Available at: http://ec.europa.eu/education/programmes/ socrates/ects/index_en.html. Accessed July1, 2007.

5. Anderson J. The role of ethics in information technology decisions: a case-based approach to biomedical informatics education. Int J Med Inform 2004;73:145-50.

6. Logan JR, Price SL. Computer science education for medical informaticians. Int J Med Inform 2004; 73:139-44.

7. Ash JS, Savi PZ, Kuperman GJ. A Consensus on Considerations for a successful CPOE Implementation. JAMA 2004;10:229-34.

8. http://www.usyd.edu.au/handbooks/health_sci/ 11_himt.shtml. Accessed March 9, 2008.

9. http://www.shrs.pitt.edu/CMS/Departments/ HIMProg.asp?id=164\&secondid=341 Accessed March 9, 2008.

10. http://www.healthinformatics.dal.ca/courses.php Accessed March 9, 2008.

\section{Correspondence to:}

Maijd Altwaiijiri, Ph.D.

College of Public Health \& Health Informatics

P.0. Box 22490, Riyadh 11426,

Saudi Arabia

Tel: +966 I 2520088 xtn. 43447

E-mail: majidt@ngha.med.sa 